\title{
mww.casopoisma.pan.pl PAN 级定 \\ Long-term Effects of Relative Humidity on Properties of Microwave Hardened Moulding Sand with Sodium Silicate
}

\author{
M. Stachowicz *, K. Granat \\ Department of Foundry Engineering, Plastics and Automation, Wroclaw University of Technology, \\ ul. Smoluchowskiego 25, 50-372 Wrocław, Poland \\ *Corresponding author. E-mail address: mateusz.stachowicz@pwr.edu.pl
}

Received 30.06.2016; accepted in revised form 10.10.2016

\begin{abstract}
Moulding sands containing sodium silicate (water-glass) belong to the group of porous mixture with low resistance to increased humidity. Thanks to hydrophilic properties of hardened or even overheated binder, possible is application of effective methods of hydrous reclamation consisting in its secondary hydration. For the same reason (hydrophilia of the binder), moulds and foundry cores made of high-silica moulding sands with sodium silicate are susceptible to the action of components of atmospheric air, including the contained steam. This paper presents results of a research on the effect of (relative) humidity on mechanical and technological properties of microwave-hardened moulding mixtures. Specimens of the moulding sand containing $1.5 \mathrm{wt} \%$ of sodium water-glass with module 2.5 were subjected, in a laboratory climatic chamber, to long-term action of steam contained in the chamber atmosphere. Concentration of water in atmospheric air was stabilized for 28 days $(672 \mathrm{~h})$ according to the relative humidity parameter that was ca. $40 \%, 60 \%$ and $80 \%$ at constant temperature $2{ }^{\circ} \mathrm{C}$. In three cycles of the examinations, the specimens were taken out from the chamber every 7 days $(168 \mathrm{~h})$ and their mechanical and technological parameters were determined. It was found on the grounds of laboratory measurements that moulds and cores hardened with microwaves are susceptible to action of atmospheric air and presence of water (as steam) intensifies action of the air components on glassy film of sodium silicate. Microwave-hardened moulding sands containing sodium silicate may be stored on a longterm basis in strictly determined atmospheric conditions only, at reduced humidity. In spite of a negative effect of steam contained in the air, the examined moulding mixtures maintain a part of their mechanical and technological properties, so the moulds and foundry cores stored in specified, controlled conditions could be still used in manufacture.
\end{abstract}

Keywords: Foundry, Sodium silicate, Humidity, Microwaves, High-silica sand

\section{Introduction}

Moulding or core sand is composed, first of all, of a base and a binder bonding base grains. In the specified composition of a mixture, importance of gas (air) filling pores of such a mixture is often omitted. So, moulding sand should be considered as a threecomponent system: sand base - binder - atmospheric air. Pores filled with air are of particular importance at removing gases created when a casting mould is poured. They have also another, less positive meaning. They are a source of the problems related to storage of finished casting moulds and cores with regard to the air filling the porous mixture. Carbon dioxide and steam contained in the air can create various chemical compounds with components of moulding sand, especially in the technology employing sodium silicate as the binder. 
Absolute humidity (or just humidity) is defined as total amount of water contained in the air in grams per $1 \mathrm{~m}^{3}$ of air. Relative humidity is defined as ratio of actual amount of water vapour contained in $1 \mathrm{~m}^{3}$ of air, at a specific pressure and temperature, to the amount needed to saturate the same volume of air at the same pressure and temperature [1]. As reported in [2], annual average relative humidity in Poland, depending on a region, ranges within 76 to $86 \%$. In the case of moulding sands based on traditional materials like high-silica sands and hydrophilic binders like sodium silicate, great importance should be attached to conditions and time of storing foundry moulds and cores.

As was demonstrated by previous research works on sodium silicate containing moulding sands, they are, after hardening by both physical [3] and chemical methods [4], especially susceptible to action of humidity [ $5,6,7]$. In the paper [8], possibilities were shown of effective reversing the hydration process that takes place in the binder after physical drying, even after the moulding mixture was used in manufacture. Among the research works on eco-friendly moulding sands with sodium silicates [9], there are some works aimed at improving their knock-out properties $[10,11]$ and resistance to humidity present in the air . They include the methods employing special coatings [12,13] and application of combined hardening methods [14]: EMCHM (ester-microwave composite hardening method) or TMHP (twice microwave heating process) [15]. However, these methods are technologically advanced and require special additives to moulding mixtures. Ensuring additionally suitable storage conditions of these moulding sands should prevent degradation of mechanical properties reached after microwave hardening.

In this research, an attempt was made to determine the effects of surrounding atmosphere with specific humidity on properties of non-modified sodium silicate containing moulding sands hardened by microwaves.

\section{Purpose and scope of the research}

The moulding mixtures used in this research were prepared of dried and cooled-down high-silica medium-size $1 \mathrm{~K}$ sand with the main fraction 0.20/0.315/0.16 from the mine "Grudzen Las" and non-modified sodium silicate (water-glass) grade 145 made by Chemical Works "Rudniki" S.A., see Table 1. A portion of $6 \mathrm{~kg}$ of moulding sand was prepared in a laboratory ribbon mixer. Per 100 weight parts of sand, 0.5 weight parts of water was dosed [16]. Next, after $60 \mathrm{~s}$ from starting the stirring process, 1.5 weight parts of the binder 145 were introduced, and mixing was continued for $240 \mathrm{~s}$.

Cylindrical, elongated and eight-shaped (dog bone) specimens were vibration thickened on the apparatus LUZ-2e. Next, the specimens were microwave heated for 4 minutes in the 32-1 microwave furnace chamber at power of $1.0 \mathrm{~kW}$.

In the examinations of resistance to the action of atmospheric air, a climatic chamber KK 115 TOP+ made by Pol-Eko S.A. was applied, with temperature stabilization at $20{ }^{\circ} \mathrm{C} \pm 1{ }^{\circ} \mathrm{C}$. During each of the 28-day measuring cycles, a different relative humidity was applied: ca. $40 \%, 60 \%$ or $80 \%$. Relative humidity values are introduced to designations of the measurement series: $\mathrm{H} 40 \%$, $\mathrm{H} 60 \%$ and $\mathrm{H} 80 \%$.
After every 7 days of maintaining the specimens in the chamber, they were taken-out and their strength values $\mathrm{R}_{\mathrm{m}} \mathrm{U}, \mathrm{Rg}_{\mathrm{g}} \mathrm{U}$ and $\mathrm{R}_{\mathrm{c}}{ }^{\mathrm{U}}$ were determined on a laboratory tester for moulding sands $\mathrm{LRuE}-2 \mathrm{e}$ made by Multiserw-Morek. Permeability $\mathrm{P}^{\mathrm{U}}$ was determined on an apparatus LPiR. Abrasion resistance $\mathrm{S}^{\mathrm{U}}$ was determined on a device designed by E. Janicki $[16,20]$, by treating the rotating $(60 \mathrm{rpm})$ cylindrical specimens with $1.77 \mathrm{~kg}$ of falling-down from height of $\sim 282 \mathrm{~mm}$ metallic shot. Observations of bonding bridges were carried-out on a scanning microscope Hitachi TM-3000 equipped with an EDS/EDX analyser.

Table 1.

Physico-chemical properties of sodium silicate used in the examined moulding sands

\begin{tabular}{ccccccc}
\hline Grade & $\begin{array}{c}\text { Molar } \\
\text { module } \\
\mathrm{SiO}_{2} / \mathrm{Na}_{2} \mathrm{O}\end{array}$ & $\begin{array}{c}\text { Oxide } \\
\text { content } \\
\left(\mathrm{SiO}_{2}\right. \\
\left.+\mathrm{Na}_{2} \mathrm{O}\right) \\
\%\end{array}$ & $\begin{array}{c}\text { Density } \\
\left(20^{\circ} \mathrm{C}\right) \\
\mathrm{g} / \mathrm{cm}^{3}\end{array}$ & $\begin{array}{c}\mathrm{Fe}_{2} \mathrm{O}_{3} \\
\text { max. } \\
\%\end{array}$ & $\begin{array}{c}\mathrm{CaO} \\
\text { max. } \\
\%\end{array}$ & $\begin{array}{c}\text { Dynamic } \\
\text { viscosity } \\
\text { min. } \\
(\mathrm{P})\end{array}$ \\
\hline 145 & 2.5 & 41.5 & 1.47 & 0.01 & 0.1 & 1 \\
\hline
\end{tabular}

\section{Results}

Results of the examinations of the effect of humidity on basic parameters of moulding sands are shown in Figs. 1 to 4.

The first analysed quantity was apparent density in $\mathrm{g} / \mathrm{cm}^{3}$ (average of three measurements) shown in Fig. 1, determined on cylindrical specimens.

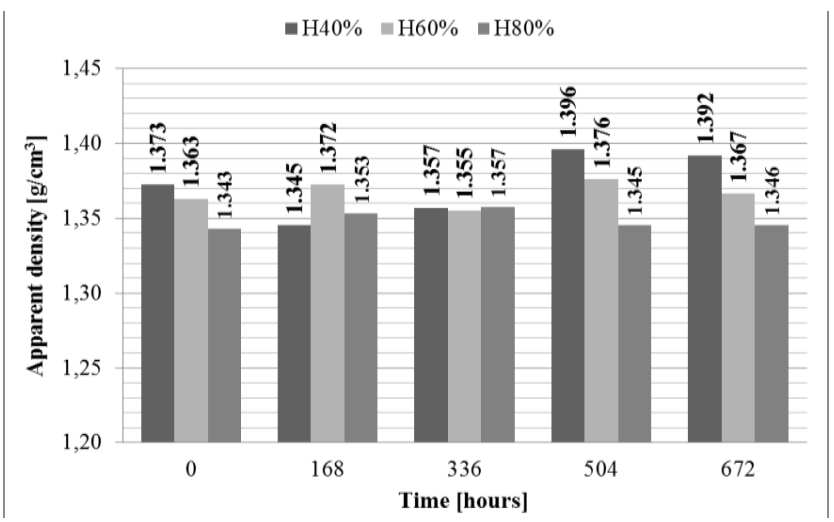

Fig. 1. Apparent density of hardened moulding sands exposed to humid air for $672 \mathrm{~h}$ in a climatic chamber

As can be seen in Fig. 1, apparent density of the moulding mixture ranged from 1.34 to $1.40 \mathrm{~g} / \mathrm{cm}^{3}$. Average density values of cyclic (every $168 \mathrm{~h}$ ) measurements were $1.37 \mathrm{~g} / \mathrm{cm}^{3}$ for the series $\mathrm{H} 40 \%, 1.37 \mathrm{~g} / \mathrm{cm}^{3}$ for $\mathrm{H} 60 \%$ and $1.35 \mathrm{~g} / \mathrm{cm}^{3}$ for $\mathrm{H} 80 \%$. Therefore, practically no effect of time of exposing the moulding mixture to humid atmosphere on its apparent density was observed.

The next indices used for evaluation of quality changes of moulding sands hardened with microwaves and held in specific atmospheric conditions were mechanical parameters: tensile strength $\mathrm{R}_{\mathrm{m}}^{\mathrm{U}}$ (Fig. 2), bending strength $\mathrm{R}_{\mathrm{g}}^{\mathrm{U}}$ (Fig. 3) and compression strength $R_{c}{ }^{U}$ (Fig. 4) expressed in SI unit $\left(\mathrm{N} / \mathrm{cm}^{2}\right)$. 
Points in the diagrams show arithmetic averages of minimum five measurements for eight-shaped and elongated specimens, and of three measurements for cylindrical specimens.

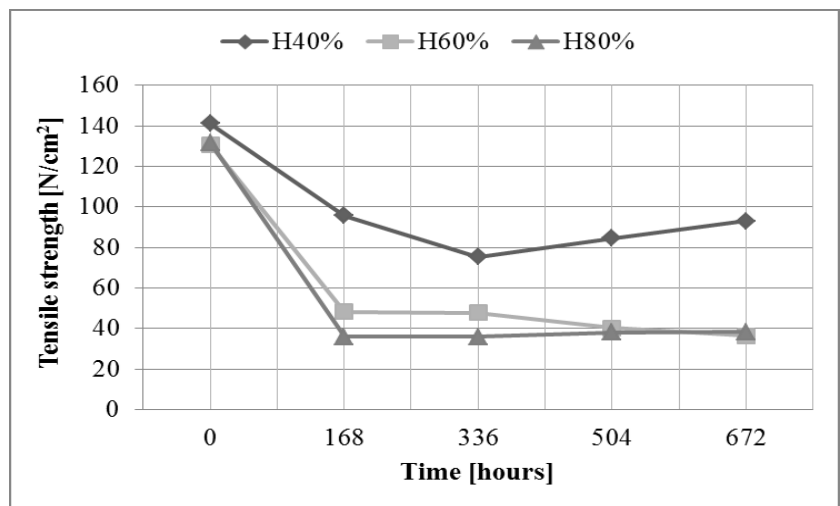

Fig. 2. Effect of humidity and exposure time on tensile strength $\mathrm{R}_{\mathrm{m}}^{\mathrm{U}}$ of moulding sand

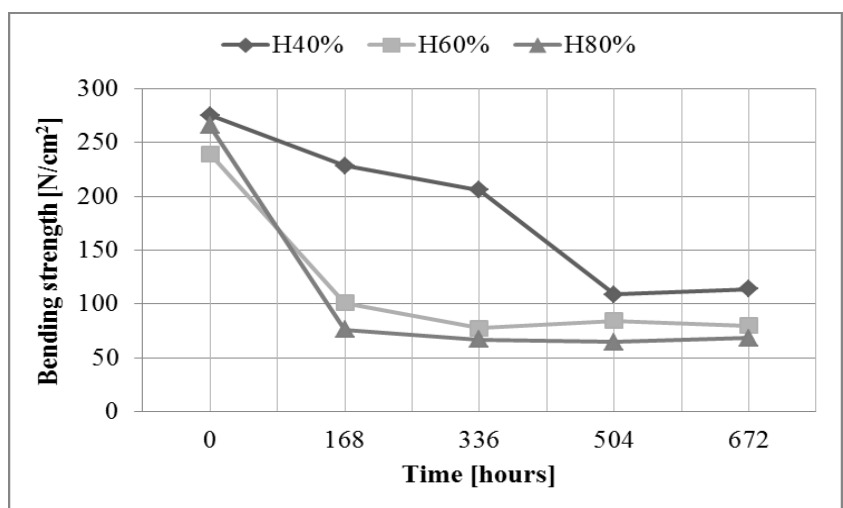

Fig. 3. Effect of humidity and exposure time on bending strength $\mathrm{Rg}_{\mathrm{g}}^{\mathrm{U}}$ of moulding sand

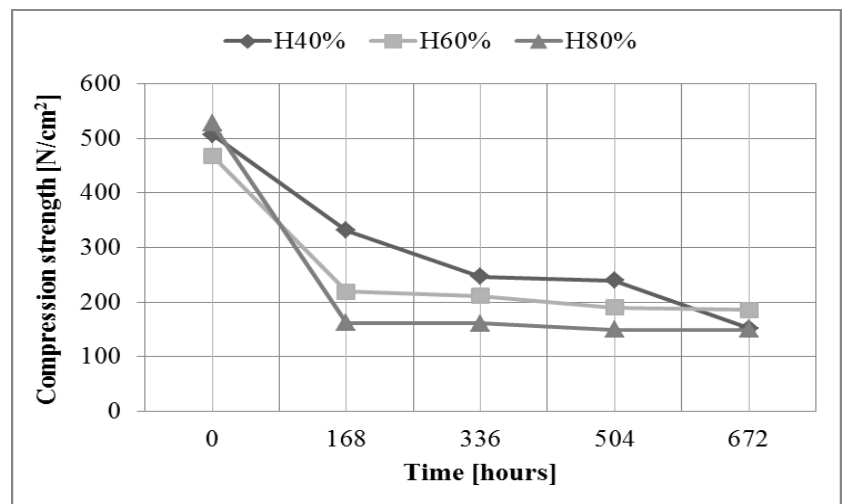

Fig. 4. Effect of humidity and exposure time on compression strength $\mathrm{R}_{\mathrm{c}}^{\mathrm{U}}$ of moulding sand

Analysis of the results obtained during the 672-h trial shows that, in the case of the series $\mathrm{H} 60 \%$ and $\mathrm{H} 80 \%$, the biggest drop of tensile, bending and compression strength occurs during the first 168 hours from the beginning of the experiment. The observed changes are best demonstrated by percentage drop of strength related to its initial value, as shown in Figs. 5, 6 and 7.

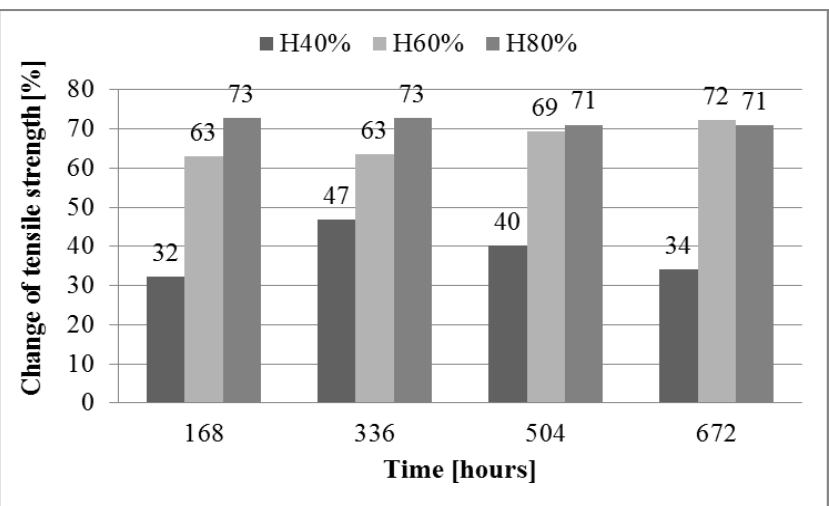

Fig. 5. Percentage change of tensile strength $\mathrm{R}_{\mathrm{m}}^{\mathrm{U}}$ with time

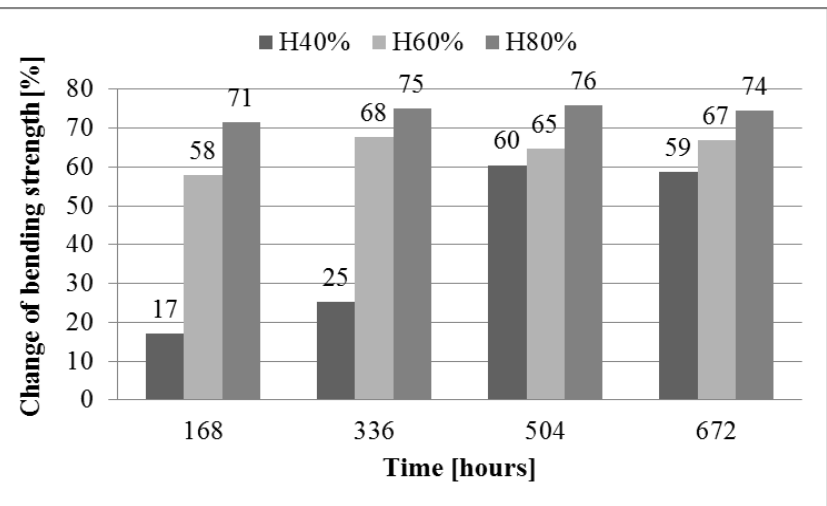

Fig. 6. Percentage change of bending strength $\mathrm{R}_{\mathrm{g}}{ }^{\mathrm{U}}$ with time

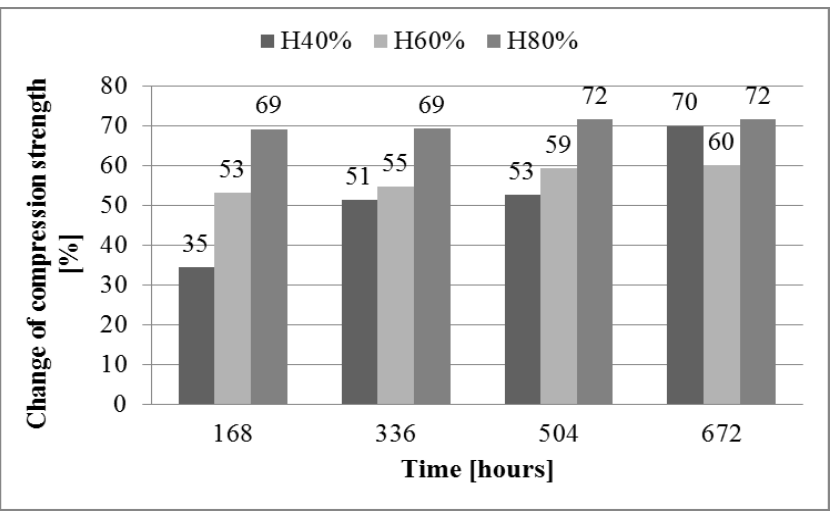

Fig. 7. Percentage change of compression strength $\mathrm{R}_{\mathrm{c}}{ }^{\mathrm{U}}$ with time

After 168 hours in the series $\mathrm{H} 80 \%$, the moulding mixture lost over $70 \%$ of its initial strength $R_{m}{ }^{U}, R_{g}{ }^{U}$ and $R_{c}{ }^{U}$, see Figs. 5 to 7. During further exposure of the moulding sand, no decline of mechanical parameters was observed. After the same time in the series $\mathrm{H} 60 \%$, the moulding sand lost $63 \%$ of $\mathrm{R}_{\mathrm{m}}^{\mathrm{U}}, 58 \%$ of $\mathrm{R}_{\mathrm{g}}^{\mathrm{U}}$ and $53 \%$ of $\mathrm{R}_{\mathrm{c}}^{\mathrm{U}}$ values. Subsequent examinations in this series after 336, 504 and 672 hours showed slow decline of strength with time, so it can be supposed that erosion of bonding bridges 
took place. From among the three examined series, the least adverse effect was found for the moulding mixtures exposed to the air with the lowest humidity, i.e. $40 \%$. In the H40\% series, the moulding sand maintained its good strength for the longest time, so that it could be still used in practice for full-value components of foundry moulds and cores. After the first 168 hours of exposure, the moulding sand lost merely ca. $32 \%$ of $\mathrm{R}_{\mathrm{m}}^{\mathrm{U}}, 17 \%$ of $\mathrm{Rg}_{\mathrm{g}}^{\mathrm{U}}$ and $35 \%$ of $\mathrm{R}_{\mathrm{c}}^{\mathrm{U}}$ values. Decline of strength during the first 168 hours proceeded much slower than in the case of two other series, see Figs. 2, 3 and 4. After 504 and 672 hours, tensile strength of the moulding mixture in this series was $50 \%$ higher than that of the series $\mathrm{H} 60 \%$ and $\mathrm{H} 80 \%$, see Fig. 2. Similar trends are visible for bending and compression strengths.

Therefore, it can be provisionally assumed that the moulding sands exposed to the air with humidity close to normal atmospheric value, as well as that reduced to $60 \%$ and $40 \%$, maintain strength values enabling normal use of moulds and cores stored in such environment, on condition that fulfilled are the basic technological requirements: permeability $\mathrm{P}^{\mathrm{U}}$ (Fig. 8) and abrasion resistance $\mathrm{S}^{\mathrm{U}}$ (Fig. 9).

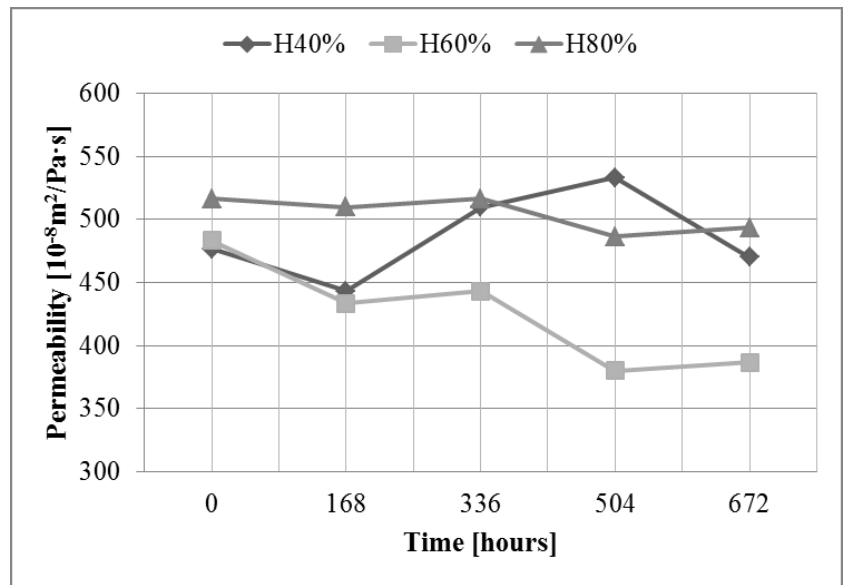

Fig. 8. Effect of humidity and exposure time on permeability $\mathrm{P}^{\mathrm{U}}$ of moulding sand

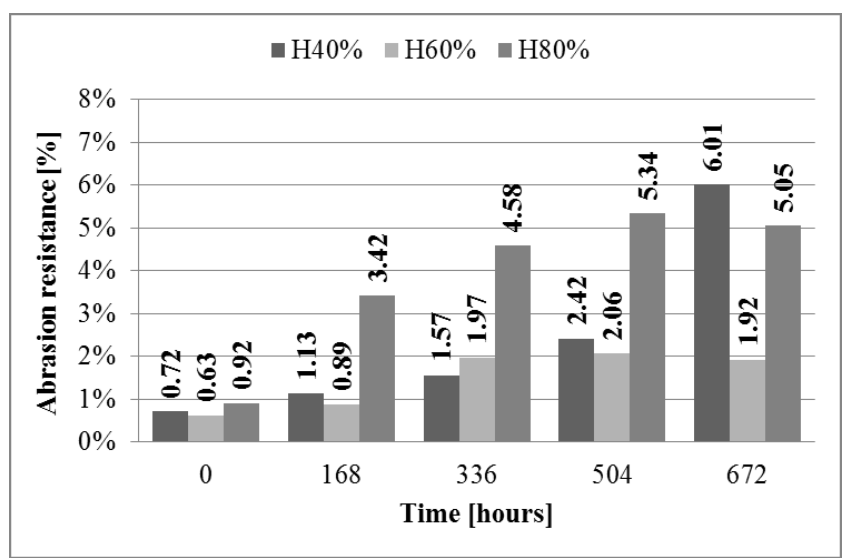

Fig. 9. Effect of humidity and exposure time on abrasion resistance $\mathrm{S}^{\mathrm{U}}$ (with loose metallic abrasive)
Permeability of the moulding sand in each of the three series was satisfactory and ranged within 400 to 500 units in the SI system $\left(\cdot 10^{-8} \mathrm{~m}^{2} / \mathrm{Pa} \cdot \mathrm{s}\right)$. In the series $\mathrm{H} 60 \%$ for $504 \mathrm{~h}$ and $672 \mathrm{~h}$ of exposure, a slight decrease of $\mathrm{P}^{\mathrm{U}}$ value by ca. $20 \%$ in relation to the initial value was observed.

The presented values of abrasion resistance $\mathrm{S}^{\mathrm{U}}$ are satisfactory for the series $\mathrm{H} 40 \%$ and $\mathrm{H} 60 \%$. Mass loss of the examined specimen exposed for 168 to 504 hours, determined in the abrasion test, reached ca. $2 \%$ and is within the acceptable limits. In the series $\mathrm{H} 80 \%$, a significant drop of abrasion resistance was observed just after first 168 hours.

\section{SEM and EDS/EDX analysis}

Mechanical and technological examinations were complemented with observations of bonding bridges on a scanning microscope. The observations were carried-out on the specimens after 672-h exposure in the climatic chamber. Surface of sand base grains coming from the specimens after mechanical testing is shown in Fig. 10. Identification and distribution of elements performed with the EDS/EDX analyser is shown in Fig. 11.

As results from observations of bonding bridges between high-silica base grains (Figs. 10c to 10f), they are characterised by numerous cracks and spalled parts of the hardened binder. During keeping the moulding sand in the atmosphere with relative humidity of $60 \%$ and $80 \%$ inside the climatic chamber, numerous discontinuities were created in the bonding bridges (marked with arrows in Figs. 10c, 10e and 10f). Visual evaluation showed that their number increases with increasing humidity of the air. Nature of the discontinuities in the whole volume of a bonding connection is similar to that of the bridges created after hardening with unheated carbon dioxide [18]. No this type diverse changes were found for the series $\mathrm{H} 40 \%$, see Figs. 10a and 10b. The observations shown in Fig. 10 are reflected in the strength values measured for fresh moulding mixtures after hardening with unheated $\mathrm{CO}_{2}$ [19]. Moreover, high chemical activity of the binder hardened by microwaves was found. In the areas of its concentration, the binder participates in creation of many new structures with texture [17] (Figs. 10a, b, 11a), fibrous (Fig. 10d) and acicular construction, see Figs. 10c, e, f and 11b. This type changes within the bonding bridges have not been observed till now in fresh moulding sands after microwave hardening. The observed unusual structures together with analyses of the elements participating in their structure are shown in Fig. 11. It results from the performed EDS analysis that the element creating the new structures is sodium.

A film of sodium silicate is present in the amorphous form, i.e. in the state of matter that does not show a long-range order [20]. The first observations led to the conclusions based on separation of phases and crystallisation of sodium oxide from a thermodynamically unstable amorphous structure [21].Separation of sodium compounds from glassy film of the hardened binder can stabilise it and thus cause cohesive and adhesive destruction of bonds in the bridges. 

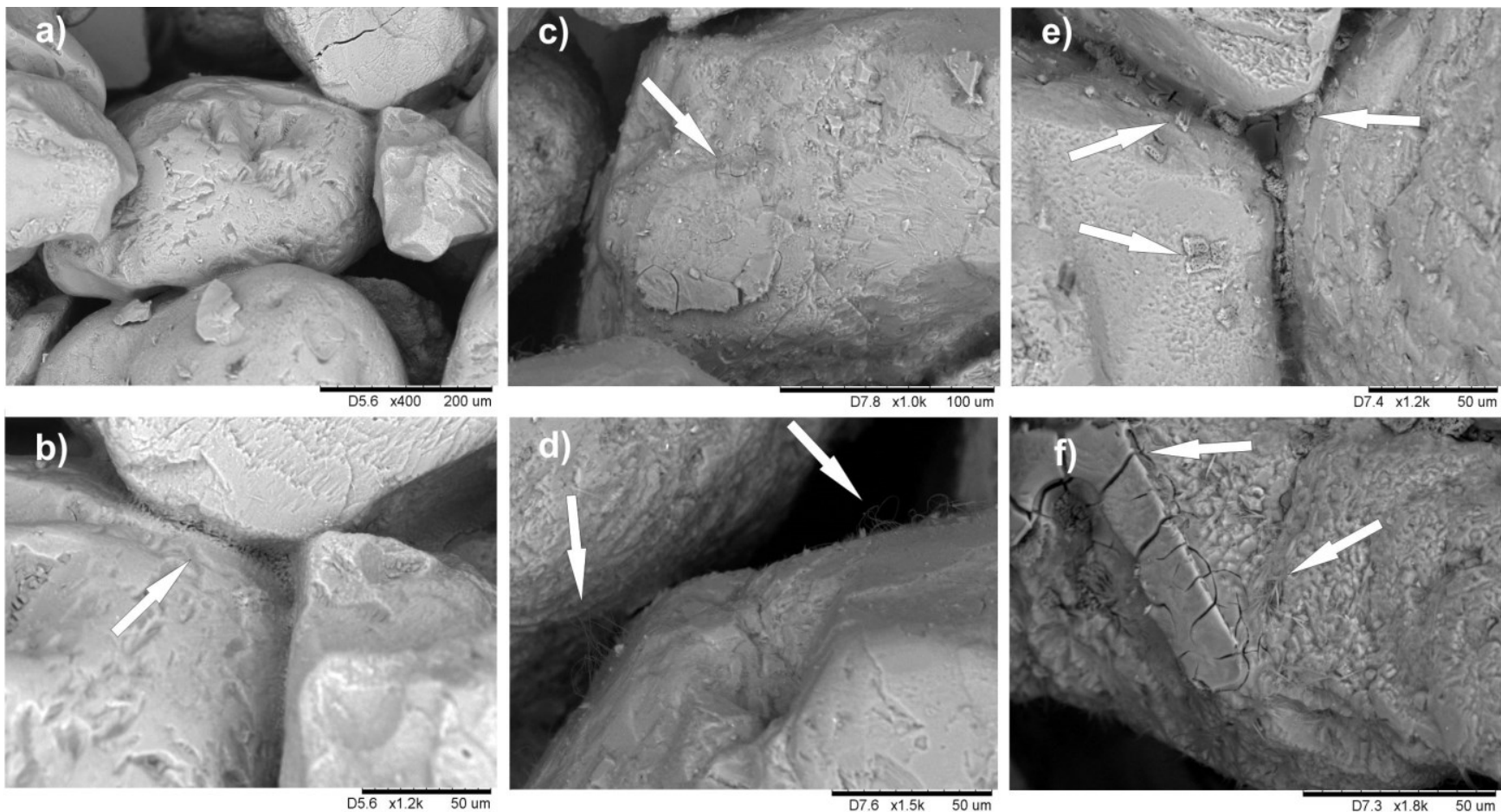

Fig. 10. Surface of high-silica base after 672-h exposure in atmosphere with humidity: $40 \%-\mathrm{a}), \mathrm{b}$ ); $60 \%-\mathrm{c}$ ), d) and $80 \%$ - e), f)

The observed phenomenon of separating sodium-rich compounds from the binder can have further, negative consequences in form of its deactivation. The mentioned deactivation means a restriction of susceptibility to the - described among others in the paper [8] - processes of hydrous reclamation of the hardened and overheated binder in order to restore its bonding properties in the reclaimed moulding sand.
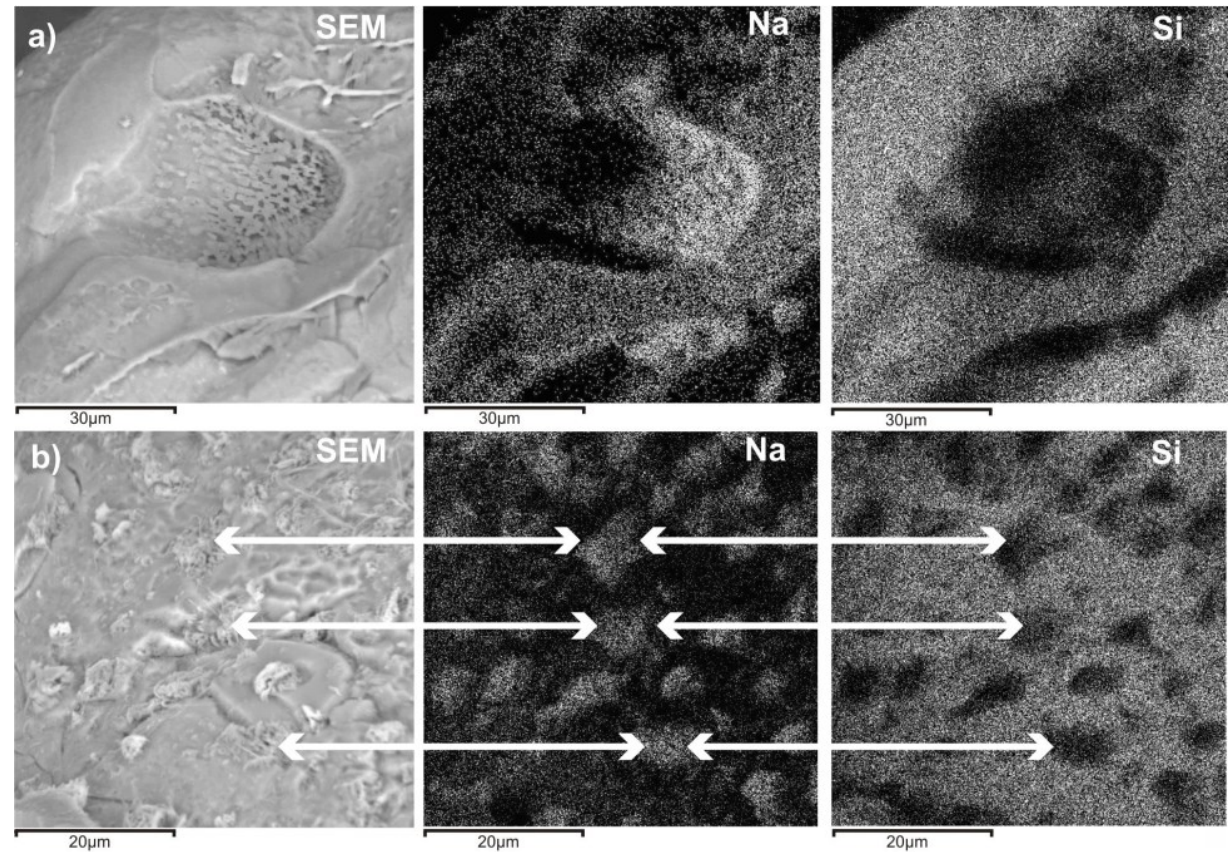

Fig. 11. Areas of binder concentration together with characteristic newly created textured structures for $\mathrm{H} 40 \%-\mathrm{a})$ and fibrous-acicular structures for: $\mathrm{H} 60 \%$ and $\mathrm{H} 80 \%-\mathrm{b}$ ) 


\section{Conclusions}

In the presented examinations, lasting $672 \mathrm{~h}$ in each series, of the effect of air humidity on properties of microwavehardened moulding sands containing sodium silicate, influence of storage conditions of foundry moulds and cores on quality of bonding bridges between base grains was confirmed. In the environment of atmospheric air with humidity $80 \%$ and $60 \%$, all its chemically active components interact with the inorganic binder. The observed changes in form of discontinuities of the bridges are similar to the known effect on unheated $\mathrm{CO}_{2}$ used for hardening sodium silicate moulding sands. Strength values of the moulding mixtures in the series with humidity $80 \%$ after 168-hour exposure are very close to those of fresh moulding sands with sodium silicate, hardened with unheated $\mathrm{CO}_{2}$.

In the conditions of humidity reduced to $40 \%$, moulds and cores made of the examined moulding materials can be stored for the time not longer than $500 \mathrm{~h}$ with no risk of a significant loss of strength and deterioration of technological parameters.

Long storage time of a moulding sand can lead to secondary hydration of microwave-hardened binder by water contained in atmospheric air. Then, a reaction can occur of secondarily hydrated sodium silicate with $\mathrm{CO}_{2}$ contained in the air filling pores of the moulding sand. The possibility of parallel occurrence of each of the described processes can not be excluded, but confirmation of this phenomenon requires continuing the research in that one of the factors: water or $\mathrm{CO}_{2}$ would be eliminated.

\section{Acknowledgement}

The research was financially supported from the grant for statutory activity No. B50120/K1012.

\section{References}

[1] Akademia Techniczno- Humanistyczna. (06.28.2016). Measurement of relative humidity of air. http://www.zt.ath.bielsko.pl/wilgotnosc powietrza.pdf (in Polish).

[2] Lorenc, H. (2005). Atlas of Polish climate edited by Halina Lorenc. Warszawa: Instytut Meteorologii i Gospodarki Wodnej. (in Polish).

[3] Owusu, Y.A., Draper, A.B., Nowicki, R.M. \& Cole, G.S. (1980). Humidity resistance of sodium silicate-bonded sands cured with microwave energy. Transactions of the American Foundrymen's Society. 8, 601-608.

[4] Wang, H.F., Lu, J.J., Chen, K.F. \& Duan, H.L. (2015). Harmless treatment of used foundry sands and dewatered municipal sludge by microwave. Metalurgija. 54 (3), 459461.

[5] Zych, J. (2007). Behaviour of moulding sands with hydrophilic binders in dry air. Archives of Foundry Engineering. 7(4), 189-192.

[6] Wang, H.F., Fan, Z.T., Yu, S., Liu, F.C. \& Li, X. (2012). Wet reclamation of sodium silicate used sand and biological treatment of its wastewater by Nitzschia palea. China Foundry. 9 (1), 34-38.

[7] Dańko, J., Dańko, R. \& Łucarz, M. (2007). Processes and equipment for reclamation of matrix of waste molding sands, Kraków: Scientific Publishing House Akapit (in Polish).

[8] Stachowicz, M. \& Granat, K. (2015). Influence of melt temperature on strength parameters of cyclically activated used-up sandmixes containing water-glass, hardened with microwaves. Archives of Civil and Mechanical Engineering. 15(4), 831-855.

[9] Izdebska-Szanda, I. \& Balinski, A. (2011). New generation of ecological silicate binders. Procedia Engineering. 10, 887-893.

[10] Bobrowski, A., Kmita, A., Starowicz, M., Stypuła, B. \& Hutera, B. (2012). Effect of Magnesium Oxide Nanoparticles on Water Glass Structure. Archives of Foundry Engineering. 12(3), 9-12.

[11] Kmita, A. \& Hutera, B. (2013). Water glass modification and its impact on the mechanical properties of moulding sands. Archives of Foundry Engineering. 13(2), 81-84.

[12] Wang, H.F., Fan Z.T., Liu, F.C. \& Li, X. (2012). Preliminary study on humidity resistance of sodium silicate sand hardened by microwave heating coated with eutectic lithium salts. Zhuzao/Foundry. 61(4), 382-385.

[13] Liu, F.C., Fan, Z.T., Liu, X., Huang, Y. \& Jiang, P. (2016). Effect of surface coating strengthening on humidity resistance of sodium silicate bonded sand cured by microwave heating. Materials and Manufacturing Processes. 31, 1639-1642.

[14] Huafang, W., Wenbang, G. \& Jijun, L. (2014). Improve the humidity resistance of sodium silicate sands by estermicrowave composite hardening. Metalurgija. 53(4), 455458.

[15] Liu, F., Fan, Z., Liu, X., Wang, H. \& He, J. (2014). Research on humidity resistance of sodium silicate sand hardened by twice microwave heating process. Materials and Manufacturing Processes. 29(2), 184-187.

[16] Stachowicz, M., Granat, K. \& Pałyga, Ł. (2016). The effect of wetting agent on the parameters of dry moulding silica sands bonded with sodium water glass. Transactions of the Foundry Research Institute. 56(1), 43-55.

[17] Stachowicz, M., Granat, K. \& Pałyga, Ł. (2016). Effect of sand wetting on physically hardened moulding sands containing a selected inorganic binder. Part 2. Archives of Foundry Engineering. 16(1), 79-84.

[18] Stachowicz, M., Granat, K. \& Nowak, D. (2010). Effect of hardening method and structure of linking bridges on strength of water glass moulding sands. Archives of Foundry Engineering. 10(spec. 2), 141-146.

[19] Stachowicz M. (2012). Effect of microwave heating and the composition of moulding sands with sodium silicate on properties of the casting molds and cores. Unpublished doctoral dissertation, Wroclaw University of Technology, Wroclaw, Polan. (in Polish).

[20] Lewandowski, J.L. (1997). Materials for moulds. Kraków: Scientific Publishing House Akapit. (in Polish).

[21] Atkins, P.W. (2007) Physical chemistry. Warszawa: Wydawnictwo Naukowe PWN. (in Polish). 